\title{
Praise for Why Games Are Good For Business
}

"Helen gives us a valuable resource to help potential clients understand serious games. Individuals considering serious games will do well to let this book be their guide, drawing upon her intuition and experience distilled into useful frameworks to understand benefits, process, and more. Filled with useful tips, tools, data, and examples, this book is a worthwhile addition to the canon."

-Clark Quinn, Executive Director, Quinnovation

“Games, simulations, and role-playing have always played a vital role in learning and development. Today, the commercial success of video games has enabled corporate organizations to improve the cost-effectiveness of their HR activities through the serious use of these technologies. The author of this book is one of the most experienced and respected experts in serious games."

-David Wortley, entrepreneur and gamification specialist

"Helen Routledge's Why Games Are Good For Business is a compelling journey through the overall landscape of serious games, what they are, why they work and who is using them to achieve market advantage. As one of the rare experts who can genuinely claim to have shaped the serious games space, Helen explores the market opportunity in various sectors and conveys how role-playing can help you understand your competitors' thinking and anticipate their next move. From the privileged perspective of a most successful game designer and production lead, Helen generously shares the techniques that games use to take learning to a completely new level by allowing you to be bad at them, stalling your progress, and then rewarding new visions of the possible that lead players to epic wins. A world where poor decisions or poor choices are never reinforced!"

-Eliane Alhadeff, serious games market editor

"As researcher and designer in the field of serious games, I have read dozens of papers and books on the subject that are aimed at academics or practitioners. Whilst these are often excellent, they invariably speak to people who are already in the field. Helen's book is the first l've read that manages to take the state of the art put it in the context of someone who might want to commission a serious game or who has an interest but isn't already researching or making games. Helen's background in psychology and extensive experience as a practitioner give her the ideal background for this book and I plan on buying a copy for anyone who commissions us to design them a serious game."

-David Farrell, Lecturer in Games Design, Glasgow Caledonian University

"Serious games are complicated and sophisticated software systems bridging specific business or education needs (e.g. training, communication, behavioural change) with the world of game-making. Consequently, designing a successful serious game is a necessarily complex and collaborative process in which all stakeholders must fully engage. In her new book Why Games Are Good For Business Helen Routledge shares her extensive knowledge and expertise as a leading serious game designer and provides the reader with a remarkably concrete and practical account of serious games, their potential benefits to businesses, and the process of making them. As an educator in the field, Helen's book is a 'must-read' for aspiring serious game designers and anyone considering a serious game approach for their business."

-Sandy Louchart, serious game researcher and lecturer,

Digital Design Studio at the Glasgow School of Art 
"This book is destined to be a classic. Well-written, easy to read, packed with highly useful information - this volume is a must for every L\&D professional interested in learning about and developing serious games. Whether your interest is advocating for serious games, finding tools and heuristics for developing serious games, getting game design ideas from other developers, or just plain learning about the topic, Helen Routledge's Why Serious Games Are Good For Business will surely deliver."

-Anne Derryberry, Designer/producer of game-based and social media-supported learning, imserious.net

"A timely book, understanding, optimizing and then utilizing serious games, and the learning theory behind them, will become increasingly important for those corporations whose L\&D departments do not want to be left behind wondering what happened."

-Michael Hogben, Learning \& Technology Manager of a large UK energy company

"This book explains in depth, with the assistance of some real case studies, the indisputable value of using serious games in business. The application of serious games in education and training has been a key theme at Europe's principal thought leadership summit EdTech Europe, which I co-founded three years ago. Through my investment and advisory company IBIS Capital we have been reviewing the serious games market for some time and are excited by the prospects for this important area of training. With such a pace of change in technology, employee profile, and global commerce, businesses ought to be thinking 'can we afford not to use serious games in our L\&D toolkit?' and this book is the perfect accompaniment on your journey of discovering why serious games are good for business."

-Charles McIntyre, CEO, IBIS Capital; Co-Founder, EdTech Europe

"Why Games Are Good For Business is the book that companies need to utilize in today's increasingly competitive economic landscape. Easy to understand, Helen Routledge helps to put into perspective the power of serious games with due acknowledgment to realworld complexities. A truly refreshing read, this book encapsulates Routledge's in-depth understanding and extensive experience in the field of serious games. A 'must-read' for all who want to bring the role of serious games to the next level."

-Ivan Boo, President, Serious Games Association (Singapore); Co-Founder, Taggle

"In this impressive book Routledge tells us about how games work saying 'the reward is the mastery of the knowledge'. What lies in these pages certainly moved me forward hugely in my efforts to master my own knowledge of games, gaming, and gamification. The in-depth coverage of psychology and learning theory is matched by the thoroughness and breadth of references to a wide range of game examples. I read this book in two sittings; it is fascinating and useful in equal measure and proves that games are safe, sticky, scalable, scorable, and stimulating."

-Spencer Holmes, thought leader in the areas of organizational change and leadership development working globally with FTSE 250 companies

"A brilliantly accessible guide to the world of serious games. This book is comprehensive, interesting, and full of practical advice and experiences. Whether you are a complete beginner to serious games or someone looking to fill in some holes in your knowledge, this book is a great place to start."

-Richard Newton, award winning author; entrepreneur; consultant 


\section{Why Games Are Good For Business}

How to Leverage the Power of Serious Games, Gamification and Simulations

Helen Routledge

Head of Design and Production, Totem Learning Ltd, UK

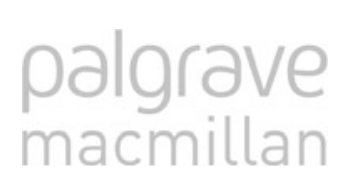




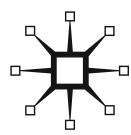

(c) Helen Routledge 2016

Softcover reprint of the hardcover 1st edition 2016 978-1-137-44896-5

All rights reserved. No reproduction, copy or transmission of this publication may be made without written permission.

No portion of this publication may be reproduced, copied or transmitted save with written permission or in accordance with the provisions of the Copyright, Designs and Patents Act 1988, or under the terms of any licence permitting limited copying issued by the Copyright Licensing Agency, Saffron House, 6-10 Kirby Street, London EC1N 8TS.

Any person who does any unauthorized act in relation to this publication may be liable to criminal prosecution and civil claims for damages.

The author has asserted her right to be identified as the author of this work in accordance with the Copyright, Designs and Patents Act 1988.

First published 2016 by

PALGRAVE MACMILLAN

Palgrave Macmillan in the UK is an imprint of Macmillan Publishers Limited, registered in England, company number 785998, of Houndmills, Basingstoke, Hampshire RG21 6XS.

Palgrave Macmillan in the US is a division of St Martin's Press LLC, 175 Fifth Avenue, New York, NY 10010.

Palgrave Macmillan is the global academic imprint of the above companies and has companies and representatives throughout the world.

Palgrave ${ }^{\circledR}$ and Macmillan ${ }^{\circledR}$ are registered trademarks in the United States, the United Kingdom, Europe and other countries.

ISBN 978-1-349-58063-7

DOI $10.1057 / 9781137448989$

ISBN 978-1-137-44898-9 (eBook)

This book is printed on paper suitable for recycling and made from fully managed and sustained forest sources. Logging, pulping and manufacturing processes are expected to conform to the environmental regulations of the country of origin.

A catalogue record for this book is available from the British Library.

A catalog record for this book is available from the Library of Congress.

Typeset by MPS Limited, Chennai, India. 
For Toby 
This page intentionally left blank 


\section{Contents}

Figures and Tables / $\mathbf{x}$

Foreword by Richard Smith $/ \mathrm{xi}$

Preface / xvi

1 Serious Games - What, Why, How and Who? / 1

Are games really the sophisticated training solution

I'm looking for? / 2

Personal motivations $/ 5$

So why now? / 6

If you only read one section of this book, make it this one! $/ 13$

So who's using them? $/ 17$

Education / 20

Environmentalism / 21

Crowdsourcing problem-solving/information / 22

So where's the evidence? / 23

Summary $/ 23$

2 If I "Feel" It - I Remember It $/ 26$

The complexity of games $/ 28$

More popular than ever $/ 28$

Choice / 30

Feedback / 32

Pacing / 36

Practice / 43

Enjoyment or fun 44

Readiness

45 
The state of flow / 46

Summary / 47

3 So What Can You Do with Serious Games? / 50

Process: The Shell Process End 2 End Demonstration $/ 50$

Service: Gaming mechanics in practice: developing

McDonald's award-winning till-training game $/ 58$

Charity: The Butterfly Project

Financial retail: Simulations for banking professionals $/ 69$

Vocational education : Using virtual and augmented reality / 75

Health care: The Harm Free Game and The Dysphagia Game / 78

Medical: Remission / 81

Market research: a face-to-face training simulation $/ 83$

Dental technology: Digital and board games

for dental technicians

84

4 A Look Behind the Scenes

88

Responding to a request for proposal $/ 91$

Setting up your team $/ 93$

Designing the solution $/ 94$

Concept development / 98

High-level design / 99

Detailed functional design $/ 100$

Application development / 101

User acceptance testing / 104

Launch / 105

Creating a buzz! / 106

Wrapping up / 110

Top tips from those who have been there and done it! $/ 111$

Bug reporting guidelines / 113

5 The Case for Genuinely Blended Learning

Origins 115

It is to do with learning styles

115

It is to do with technology

117

Creating a true blend / 117

Experiences creating blended programs / 125

What does blended learning mean to you? 
6 How Was It for You? 138

Return on investment vs return on engagement

So where's the evidence? / 143

Summary

147

7 Making a Difference to YOU

149

Game and digital literacy / 149

Corporate training / 151

Education / 155

Health and crowdsourcing of information $/ 161$

The third sector / 164

8 Don't Be a Technology Magpie / 165

The pace of change / 168

Leverage what you have / 169

Don't get swept up in the hype $/ 171$

Summary / 173

9 How to Get Involved - Next Steps for

YOUR Organization 175

The quality plan / 175

Roles, responsibilities and accountabilities / 177

Development checklist $/ 180$

Process checklist / 181

Budget guidelines / 185

Building harmonious development relationships $/ 188$

Common areas of contention between clients and vendors

10 What's Next for Serious Games?

190

The rise and rise of Serious Games / 190

Enabling practice and empowering learners in education $/ 192$

Gamification / 195

Virtual reality / 196

Augmented reality / 197

XAPI - the new standard for tracking $/ 198$

Concluding thoughts $/ 200$

References / 203

Index / 206 


\section{Figures and Tables}

\section{Figures}

2.1 An illustration of pacing through

Star Wars Episode IV: A New Hope / 40

2.2 An illustration of pacing through Assassin's Creed

41

2.3 An illustration of the concept of flow and the sweet spot between boredom and frustration $/ 47$

10.1 The future of simulation products $/ 192$

\section{Tables}

1.1 Glossary / 24

4.1 Client and vendor roles / 90

4.2 Typical Serious Game release gates and criteria $/ 103$

4.3 Bug tracking record keeping / 104

9.1 Project roles, responsibilities and accountabilities $/ 178$

9.2 Development checklist / 180

9.3 Project process checklist $/ 181$ 


\section{Foreword}

Whilst veteran is not a term I enjoy associating with myself, when it comes to the context of this book it is an apt term. For nearly 15 years I have struggled with peaks of "inflated expectations," fought through the troughs of "disillusionment" and steered my company up the slopes of "enlightenment."

During those 15 years I have used my significant business experience, entrepreneurship and emotional resilience to farrow a path less trodden by most, to pioneer Serious Games toward the point we are now, where, in my opinion, the technology and approach should be in every organization's learning mix. This book not only shows you how but who has already done this, why they did it and what the outcomes were - enjoy.

My own personal passion, and Helen's too, is the power of Serious Games to deliver truly transformational learning experiences. Typically, when you gain a passion for something there is a trigger event which started that passion. Attending your first football match, running your first race, experiencing the opera - whatever it is, there is a trigger. My interest in Serious Games, and more specifically Serious Games for corporate training and education, came from two trigger events, both including my son David. The first happened while frequenting my local watering hole. I was trying to distract my effervescent 9-year-old son by asking him to read the information below the painting of HMS Atherstone displayed on the wall. "No need to," he said. "It's a Hunt-class destroyer with a top speed of 29 knots. HMS Atherstone played a key role as part of Operation Chariot, the St Nazaire Raid, an amphibious assault on the port of St Nazaire in 
France with the objective of destroying the gates of the Normandie dock by ramming them with an explosive-packed destroyer, Campbeltown, and so prevent the dock's use by the German battleship Tirpitz." To say I was blown away is an understatement. "How do you know all that?" I asked. "I was on that ship last night Dad! In Call of Duty, of course." He went on to explain that you did not want to be one of the first over the front of the boat as you are sure to get shot but you should exit via the rear and pass down the starboard side to avoid detection. So not just a history lesson but also strategy, planning, presentation, emotional resilience and other life skills too.

My second trigger moment also involved David and highlighted the power of Serious Games in the business and management skills area. Being dyspraxic and having challenges with fine motor skills, you would think it would be very difficult for him to reach the top few echelons of the world's players, but such was his engagement and desire, he mastered a range of soft skills to achieve what he wanted, notably to be part of a crack Call of Duty (COD) team. Strategy, finance, research and presentation skills allowed him to understand the key elements required to be a team lead in $C O D$. Take high-speed internet to secure the best servers for example; he researched how to do this and what was required, he put together a business case to show how changing to such a service provider would reduce our outgoings (understanding his customer's needs). He presented this to me in such a way I thought he was doing me a favor when all along he was achieving his COD goals. If a 9-year-old can learn all that from a game, then what could well-designed and implemented experiential learning experience, that is, a Serious Game, do in your organization?

The Serious Games industry truly has been on a fascinating journey! Triggered by technology and gamer enthusiasm in the late 1990s and early 2000s, Serious Games reached the Peak of Expectations (Gartner's Hype Cycle) during the mid-2000s before, in large part, the Banking Crash of 2008/09 sent them plummeting in to the Trough of Disillusionment. But was this all bad? Perhaps it separated out the wheat from the chaff in the industry, the remaining developers returning stronger than ever, surfing today's technology tsunami. Ascending the Slope of Enlightenment, the 
Serious Games industry steadily approached the Plateau of Productivity propelled by the ever-increasing adoption of technology, the ever-lowering costs of hardware and software development, by the ever-maturing "gamer" progressing into roles of commissioning and procurement, the ever-increasing acceptance of the value of learning by doing - Kolb's experiential learning theory could almost be describing gaming.

One word of caution though, we are not talking about a modern day "snake oil" in Serious Games. While snake oil was sold in the Wild West of the 19th century to cure all ailments on its own, Serious Games are not snake oil. A claim by early developers that they "cure all" was one of the reasons for Serious Games plummeting in to the Trough of Disillusionment. However, use Serious Games correctly in your training program, and you will see immediate, transformational benefits which are quantified and detailed in Helen's book.

I first came across Helen when she joined my then employer as a Game and Instructional Designer. Poached from a competitor, Helen was already highly regarded in the emerging Serious Games sector. Helen earned a reputation for herself by speaking eloquently and knowledgeably at various conferences and seminars around the world and, having worked on many award-winning projects over the years, Helen has a true breadth of experience that few can equal. Those few who can, seldom if ever have the mix of knowledge foundations of both "hardcore" gaming and deep understanding of the psychology of learning and how and where the two combine. It takes a unique person to be able to talk as equals to a team of game devs (gaming slang) as well as L\&D (learning and development) professionals.

There are a lot of people who claim to have expertise in Serious Games but from my experience in very few who truly possess it. Our industry falls into two halves, organizations from the gaming sector and those from the learning and development industry. Organizations from the gaming sector vary from "one-man bands" who have a passion for games and realize they can do good, through to large global games developers who have the technology and skills to develop games and see Serious Games as a potential new revenue source. Organizations from the L\&D sector are 
more varied and include e-learning companies who want to differentiate themselves and training companies looking to enhance their classroom offering or move their training proposition online to reach new audiences at lower cost. We also see management consultancies who understand the need for more engaging and effective training and I would include a lot of forward-thinkers who believe gaming has a role in their specialism in training, but who are not truly sure how to go about implementing them. All the above organizations would benefit from this book.

Over the last ten years I have considered it a pleasure to work alongside Helen on a significant number of wide-ranging and varied projects from teaching new hires accountancy for a global accountant to diversity and inclusion using sci-fi and aliens. Whatever the task, whatever the learning objective, Helen unleashes her imagination at any opportunity to create innovative but highly effective games-based learning.

Helen's depth of knowledge of games and pedagogy is right up there with the best in the industry. One interesting example I can give is Helen's inspiration from the gameplay in the Nintendo DS game Phoenix Wright: Ace Attorney to teach sales skills. Not an obvious choice perhaps, but bear with me. Phoenix Wright: Ace Attorney stars Phoenix Wright, a rookie defense attorney. Other characters in the game include Miles Edgeworth, a rival prosecutor; Dick Gumshoe, a scatter-brained detective, and Larry Butz, an old friend of Phoenix. The game features five court cases divided into episodes. Each case flips between two game modes: investigation and the actual trial. In the investigation aspect of the game, Phoenix gathers evidence and speaks to characters involved in the case. In the trial aspect of the game, Phoenix defends his client using said evidence; cross-examines witnesses and solves the mystery surrounding each case. The court perspective is usually in the third person, while the perspective outside of court is in the first person. Helen used this style of gameplay and applied it to the sales process with two game modes: investigation (research and planning) and the actual trial (the sales meeting itself). The result was highly engaging sales process training where other in-game characters took on the roles of sales managers, clients, receptionists and fellow sales colleagues. 
Like Helen, I have a healthy skepticism of the gamification trend, and while it has undoubtedly grown the sector, it has also undermined and undervalued what a "serious" Serious Game aims to achieve. Serious Games change behaviors, challenge attitudes, test unconscious biases, assesses skills and so on. Gamification should be used to enhance the above and more but should not be confused with Serious Games; they are two different beasts, as this book will explain.

As with most new technologies, the initial implementations rarely live up to the hype, and Serious Games are no exception. As a judge on several awards panels and as an industry "veteran" of 15 years I have seen a lot of well-meaning but underperforming Serious Games simply miss the mark. The usual factors of being under financed, designed by a keen gamer with little business acumen or an over-specified and over-hyped "glamour" project motivated by academia's vanity rather than commercial or logical motives.

But that's why I highly commend this book as Helen will show you the best ways to avoid these hazards and explain how to get the best out of your Serious Games projects.

Richard Smith

June 2015 


\section{Preface}

I always knew games had power: power to transport me to another world, power to generate deep and meaningful emotions about virtual characters, and even the power to influence my dreams. I count myself as extremely lucky to have grown up in what must surely be classed as one of the most exciting times in the 20th century. With the advent of the home gaming console, my world was opened up to being a world-renowned racing driver, a brawling street fighter, an explorer of alien worlds or an adventurer to banish evil, all from the comforts of my bedroom.

What started off as a fun pastime stayed that way for many years until I started on my academic career. I studied Behavioral Sciences at the University of Abertay, Dundee, a university world famous as the first to offer a dedicated Game Development course. Whether it was fate or a plan buried deep within my subconscious, I ended up studying psychology at a university steeped in games design, games development and games heritage.

My love for games very much influenced my studies and I hoped to evaluate through my research how much games impacted our memories. As they have a tendency to do, my research hypothesis morphed and developed and I ended up evaluating the effectiveness of games for corporate training. What I experienced in the early days of my research cemented my belief in the power of games to influence behavior.

I have been designing Serious Games for well over a decade and I've seen the Serious Games sector develop from its indie days into a serious business proposition, being pushed by small groups of dedicated gamers 
like myself to big business now seeking out developers. Despite all the work we do in the sector, something was always missing. Games as an entertainment medium sometimes get a hard press, and Serious Games are often tarred with the same brush - the subtle and not-so-subtle differences glossed over or misunderstood. I have found myself having the same conversations many times over about why games are great for learning, why they work, and how they come to be. Part of my role is to present at conferences around the world and impart my knowledge on these areas, and that's where the idea for the book was born. If the Serious Games space is to grow, we need experts to share their knowledge and experiences of best practice, examples of where games have worked and provide some practical tips and tools on how to make it happen. That's exactly what you will find in the following pages.

It is my hope that by reading this book you will see the value of Serious Games as an addition to your L\&D toolkit, that you are able to build a business case for your managers and you have the tools and processes at hand to help you deliver your very own Serious Game.

It has been quite a challenge to condense a decade's worth of experience into one book, but I have thoroughly enjoyed the reflection and the connections I have made to other developers, subject matter experts and users of Serious Games during the process.

I'd like to take this opportunity to thank all the contributors to the book who have written case studies, sent me tips, shared anecdotes or just been there to bounce ideas around with. I'd especially like to thank Mike Johnson, as without him this book wouldn't have happened. I'd also like to thank my family, friends and colleagues who have supported me with endless cups of tea, pieces of cake and positive words.

It is my genuine intention to share my knowledge and experience. I hope you enjoy reading this book as much as I have enjoyed writing it. 